\title{
Management of post-LASIK dry eye: a multicenter randomized comparison of a new multi-ingredient artificial tear to carboxymethylcellulose
}

This article was published in the following Dove Press journal:

Clinical Ophthalmology

\author{
Avi Wallerstein ${ }^{1,2}$ \\ W Bruce Jackson ${ }^{3}$ \\ Jeffrey Chambers ${ }^{4}$ \\ Amir M Moezzi ${ }^{5}$ \\ Hugh Lin $^{6}$ \\ Peter A Simmons ${ }^{6}$ \\ 'Department of Ophthalmology, \\ McGill University, Montreal, QC, \\ Canada; ${ }^{2}$ LASIK MD, Montreal, QC \\ Canada; ${ }^{3}$ University of Ottawa Eye \\ Institute of the Ottawa Hospital, \\ Ottawa, ON, Canada; ${ }^{4}$ Kelowna Eye \\ Care Center, Kelowna, BC, Canada; \\ ${ }^{5}$ Centre for Ocular Research \& \\ Education (CORE, formerly Centre \\ for Contact Lens Research), School \\ of Optometry \& Vision Science, \\ University of Waterloo, Waterloo, ON,

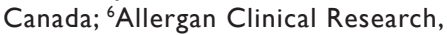 \\ Allergan plc, Irvine, CA, USA
}

Purpose: To compare the efficacy and safety of a preservative-free, multi-ingredient formulation of carboxymethylcellulose $0.5 \%$, hyaluronic acid $0.1 \%$, and organic osmolytes (CMC-HA), to preservative-free carboxymethylcellulose $0.5 \%$ (CMC) in the management of postoperative signs and symptoms of dry eye following laser-assisted in situ keratomileusis (LASIK).

Methods: This was a double-masked, randomized, parallel-group study conducted in 14 clinical centers in Canada and Australia. Subjects with no more than mild dry eye instilled CMC-HA or CMC for 90 days post-LASIK. Ocular Surface Disease Index ${ }^{\odot}$ (OSDI; primary efficacy measure), corneal staining, tear break-up time (TBUT), Schirmer's test, acceptability/ tolerability surveys, and visual acuity were assessed at screening and days 2, 10, 30, 60, and 90 post-surgery. Safety analyses included all enrolled.

Results: A total of 148 subjects (CMC-HA, $n=75 ; \mathrm{CMC}, \mathrm{n}=73$ ) were enrolled and assigned to receive treatment, and 126 subjects completed the study without any protocol violations. PostLASIK, dry eye signs/symptoms peaked at 10 days. OSDI scores for both groups returned to normal with no differences between treatment groups at day $90(P=0.775)$. Corneal staining, Schirmer's test, TBUT, and survey results were comparable. Higher mean improvements in uncorrected visual acuity were observed in the CMC-HA group at all study visits, reaching statistical significance at day $30(P=0.013)$. Both treatments were well tolerated.

Conclusion: CMC-HA-containing artificial tears relieved post-LASIK ocular dryness as well as $\mathrm{CMC}$ alone, and demonstrated incremental benefit in uncorrected vision, with a favorable safety profile. Results support use of CMC-HA eye drops to reduce signs and symptoms of ocular dryness post-LASIK.

Keywords: LASIK, dry eye, artificial tears, carboxymethylcellulose, hyaluronic acid, ocular surface disease

\section{Plain language summary}

Why was the study done? Dry eye is common after laser-assisted in situ keratomileusis (LASIK) surgery. This study was conducted to investigate whether the addition of hyaluronic acid (HA) to a standard carboxymethylcellulose (CMC)-based artificial tear formulation further improves signs and symptoms of dry eye following LASIK.

What did the researchers do and find? Improvements in signs and symptoms of dry eye were comparable between the novel artificial tear containing CMC and HA and a standard CMC-only formulation after 90 days. Higher mean improvements in uncorrected visual acuity were observed in the CMC plus HA group at all study visits, reaching statistical significance at day 30 .

What do the results mean? The presence of HA may enhance recovery of the ocular surface epithelium, and improve surface optics, with a resultant benefit in visual outcomes in comparison with the standard CMC eye drop.
Correspondence: Avi Wallerstein LASIK MD, 1250 Rene-Levesque Blvd W, Level MD, Montreal, QC H3B 4W8, Canada

$\mathrm{Tel}+15149330133$

Email awallerstein@lasikmd.com 


\section{Introduction}

Laser-assisted in situ keratomileusis (LASIK) is a common ophthalmic surgical procedure. Dry eye is a frequent occurrence after LASIK, and in significant cases, a reason for referral to tertiary eye centers. Dry eye symptoms are reported by up to $95 \%$ of patients immediately post-LASIK and up to $60 \%$ of patients 1 month post-surgery. ${ }^{1}$ Symptoms typically peak between 1 and 3 months, and chronic dry eye lasting at least 6 months after surgery has been reported in $10 \%-40 \%$ of patients. ${ }^{2-4}$ In an analysis of 143 United States Army personnel, dry eye was observed in $0.8 \%$ at 12 months post-LASIK. ${ }^{5}$ Several factors may contribute to the development of dry eye post-LASIK including iatrogenic corneal nerve damage, conjunctival goblet cell loss caused by suction devices, postoperative inflammation that could exacerbate a preexisting dry eye condition, and tear dysfunction or disruption of tear distribution during blinking from corneal surface changes. ${ }^{1}$

Similar to dry eye of other etiologies, artificial tears (preferably preservative-free) are typically the first-line treatment for post-LASIK dry eye. Carboxymethylcellulose (CMC)based artificial tears have been shown to be more effective in controlling dry eye symptoms after LASIK when compared with saline, ${ }^{6}$ or hydroxypropyl methylcellulose $0.3 \%$ and dextran $0.1 \%$ in bicarbonate buffer. ${ }^{7}$ A preservative-free hyaluronic acid (HA) $0.15 \%$ eye drop (Hylabak ${ }^{\circledR}$ or Hyabak $^{\circledR}$, Thea Pharmaceuticals, Clermond-Ferrand, France) has also been shown to effectively reduce signs of dry eye postLASIK. ${ }^{8}$ With its intrinsic properties of water retention, viscoelasticity, and promotion of corneal epithelial wound healing, ${ }^{9} \mathrm{HA}$ increases viscosity, and hydrates and lubricates the ocular surface.

A multi-ingredient formulation containing CMC 0.5\% and HA $0.1 \%$ (Refresh Optive Fusion ${ }^{\circledR}$, Allergan plc, Dublin, Ireland) has been recently introduced to the dry eye armamentarium. ${ }^{10,11}$ The organic osmolytes, glycerin and erythritol, are also included in this eye drop to reduce the cellular stress level of the ocular surface. ${ }^{12}$ In a population with a range of dry eye signs and symptoms, a large Phase III study found this preserved formulation to be noninferior to a standard preparation containing $\mathrm{CMC}$ alone in reducing signs and symptoms of dry eye. ${ }^{13}$

In the current study, the safety and efficacy of a preservative-free, multi-ingredient CMC-HA formulation (Refresh Optive Fusion ${ }^{\circledR}$ Sensitive, Allergan plc; not commercially available in all countries), similar to the preserved formulation (Refresh Optive Fusion ${ }^{\circledR}$, Allergan plc) but containing a third protective osmolyte, L-carnitine, was compared with preservative-free CMC 0.5\% (Refresh Plus $^{\circledR}$,
Allergan plc) in the management of ocular dryness following LASIK surgery.

\section{Methods}

\section{Study design and subjects}

This double-masked, randomized, parallel-group trial (ClinicalTrials.gov identifier: NCT01886690) was conducted between August 2013 and August 2014 at 13 Canadian centers and at one center in Australia in accordance with Good Clinical Practice guidelines. Independent ethics committee approval of the protocol was obtained from each site (Table S1). Adult candidates for bilateral LASIK surgery for myopia or hyperopia who provided prior written informed consent were enrolled. Key inclusion and exclusion criteria are summarized in Table 1.

Table I Key inclusion and exclusion criteria assessed at baseline (day I)

Inclusion criteria

- Male or female $\geq 18$ and $\leq 60$ years of age and in good general health

- LASIK flap creation with femtosecond laser

- Pre-LASIK best-corrected visual acuity of 20/32 or better in each eye

- Normal pre-LASIK topography by Corneal Irregularity Measurement (Humphrey Atlas) or Index of Surface Variance (Pentacam ${ }^{\circledR}$ ) or Corneal Irregularity Index (Orbscan ${ }^{\mathrm{TM}}$ ), and normal Wavefront aberrometry

- Successful completion of the surgical procedure in both eyes with no flap complications, no central epithelial defects on flap, and no requirement for bandage contact lens

Exclusion criteria

- Signs or symptoms of dry eye greater than mild severity (OSDI score $>22$ and/or corneal staining score of $>$ grade 2 [modified NEI grid] in a single zone or a cumulative score of $>4$ in all 5 zones)

- Preoperative antimetropia (ie, I eye myopic, I eye hyperopic)

- Soft contact lens wear within 7 days or rigid contact lens wear within 30 days before LASIK or during the study period

- Scheduled or planned ocular surgery (other than current LASIK surgery), systemic surgery, or other procedure during the study that may impact study participation

- Starting systemic medication (OTC, prescription, herbal, or nutritional supplement), which may affect dry eye or vision $<3$ months before screening or anticipated dose adjustment during the study

- Current use of topical ophthalmic medication other than prescribed for use in pre- or postoperative care; use of Restasis ${ }^{\circledR}$ or other topical ophthalmic cyclosporine $\leq 6$ months before screening; use of topical glaucoma medication or suspicion of glaucoma

- Active ocular infection, ocular inflammation, ocular allergy, or history of herpes keratitis

- Corneal disorder or abnormality affecting corneal sensitivity or normal spreading of the tear film and/or severe blepharitis or inflammation of the lid margin that may interfere with results

- Insertion of punctal plugs within 6 months before screening

- History of prior intraocular or anterior segment surgery (eg, radial keratotomy, cataract surgery, vitrectomy), and/or history of intraocular or anterior segment trauma

Abbreviations: LASIK, laser-assisted in situ keratomileusis; OSDI, Ocular Surface Disease Index ${ }^{\odot}$; NEI, National Eye Institute; OTC, over-the-counter. 


\section{Study visits and treatment}

Visits were scheduled 1-30 days before LASIK surgery (screening), on the day of surgery (baseline/day 1), and on postsurgical days $2,10,30,60$, and 90 . On day 1 after successful completion of LASIK, subjects were randomized 1:1 to receive preservative-free CMC-HA or CMC alone (Table 2), according to a scheme prepared by Allergan's biostatistics department. Treatment group assignment was also stratified by worse eye preoperative refractive error (manifest refraction spherical equivalent) into one of three categories: standard myope $(-1.00$ to $-6.00 \mathrm{D})$, moderate myope ( -6.125 to $-8.00 \mathrm{D})$, or hyperope $(+1.00$ to $+5.00 \mathrm{D})$.

Subjects administered one or two drops every hour while awake on days 1 and 2 , and at least every 2 hours while awake from days 2 to 10 . At the day 10, 30, and 60 study visits, investigators prescribed one of the following regimens based on the patient's dry eye signs and symptoms: at least every 2 hours while awake; six to eight times per day; three to five times per day; or one or two times per day. Gatifloxacin $0.3 \%$ ophthalmic drops $\left(Z_{y m a r}{ }^{\circledR}\right.$, Allergan plc) and prednisolone acetate $1.0 \%$ ophthalmic suspension (Pred Forte ${ }^{\circledR}$, Allergan plc) were used post-surgery for $\sim 10$ days.

\section{Outcome measures}

The primary efficacy measure was the Ocular Surface Disease Index ${ }^{\odot}$ (OSDI) score at post-LASIK day $90 .{ }^{13,14}$ Uncorrected distance visual acuity (UDVA) was a key secondary efficacy measure. A LogMAR chart at $3 \mathrm{~m}$ was used to measure UDVA, and the LogMAR line read was considered the last line that a subject could read three or more letters. Other secondary measures included corneal staining ${ }^{15}$ tear break-up time (TBUT) with sodium fluorescein, and Schirmer's test (with anesthesia). All assessments were performed in each eye. Symptom surveys graded on visual analog scales

Table 2 Study artificial tear formulations*

\begin{tabular}{|c|c|c|}
\hline \multirow{2}{*}{$\begin{array}{l}\text { Brand } \\
\text { name }\end{array}$} & CMC-HA & CMC \\
\hline & $\begin{array}{l}\text { Refresh Optive Fusion }{ }^{\circledR} \\
\text { Sensitive }^{\ddagger}\end{array}$ & Refresh Plus ${ }^{\circledR}$ \\
\hline Composition & $\begin{array}{l}\text { CMC } 0.5 \% \text {, HA } 0.1 \% \text {, } \\
\text { glycerin, sodium lactate, } \\
\text { L-carnitine, erythritol, } \\
\text { potassium chloride, calcium } \\
\text { chloride, magnesium } \\
\text { chloride, purified water, } \\
\text { and sodium hydroxide to } \\
\text { adjust } \mathrm{pH} \text { to } 6.8\end{array}$ & $\begin{array}{l}\text { CMC } 0.5 \% \text {, sodium } \\
\text { lactate, sodium } \\
\text { chloride, potassium } \\
\text { chloride, calcium } \\
\text { chloride, magnesium } \\
\text { chloride, purified water, } \\
\text { and sodium hydroxide } \\
\text { to adjust } \mathrm{pH} \text { to } 6.5\end{array}$ \\
\hline
\end{tabular}

Notes: *Sterile and isotonic formulations packaged in unit dose vials; manufactured by Allergan plc, Dublin, Ireland. ${ }^{\ddagger}$ Trade name in Canada, not commercially available in all countries.

Abbreviations: CMC, carboxymethylcellulose 0.5\%; CMC-HA, carboxymethylcellulose $0.5 \%$, hyaluronic acid $0.1 \%$. of 0 (no symptom) to 100 (maximum symptom), and an acceptability questionnaire, were administered. Subjects reported average daily dosing frequency. Safety measures included adverse events (AEs), biomicroscopy findings, intraocular pressure (IOP), and corrected distance visual acuity (CDVA).

\section{Data analysis}

The per-protocol (PP) population (randomized subjects who had no significant protocol violations) was used for the primary efficacy analysis. The intent-to-treat (ITT) population (all randomized subjects) was used for supportive and sensitivity efficacy analyses. The safety population consisted of all treated subjects.

For the primary efficacy variable, OSDI questionnaire score at day 90, noninferiority of CMC-HA compared with CMC in the PP population was tested using an analysis of variance (ANOVA) model with treatment and stratification factors of preoperative refraction strata (standard myope, moderate myope, or hyperope) as fixed effects. Using the CI procedure, a prespecified margin of less than 4.7 units for the upper limit of the two-sided 95\% CI based on treatment differences was set to consider the CMC-HA formulation noninferior to $\mathrm{CMC} .{ }^{16}$ Other analyses of OSDI score included comparisons at each scheduled visit, changes from baseline at all visits other than day 90, and comparison of subscale domain scores and subgroup analyses of OSDI scores for each preoperative refraction randomization stratum.

UDVA and CDVA were recorded and analyzed in letters read. For example, 20/50 equivalent was reported as 35 letters, and 20/20 plus two letters as 57 letters. Change from baseline in corneal staining was analyzed using the Wilcoxon rank-sum and Wilcoxon signed-rank tests. Schirmer's test, TBUT, UDVA, symptoms and acceptability surveys, product usage (daily dosing frequency), as well as IOP and CDVA safety measures were analyzed by the same ANOVA model as the primary efficacy analysis. Significance level for all analyses was $P<0.05$.

A sample size of 91 subjects per treatment group (182 total subjects) was planned to provide $90 \%$ power to determine noninferiority in OSDI score at day 90 , based on a one-sided type I error rate of 0.025 and the assumptions of no treatment difference and a common SD of 9.7.

\section{Results Subject disposition and baseline characteristics}

Of the 207 subjects screened, 148 subjects were enrolled and randomized (75 subjects, CMC-HA group; 73 subjects, 
CMC group) and 146 (98.6\%) completed the study. Among the randomized subjects, 126 had no significant protocol violations and 125 (99.2\%) completed the study. Since the number of patients was less than initially planned, the power for the primary efficacy analysis was $83.4 \%$ rather than $90 \%$ as intended.

Baseline characteristics were similar between the two groups; mean (SD) age was 33.3 (8.9) years (range, 20-56 years) and $90.5 \%$ of subjects were Caucasian. Corneal topography and aberrometry measurements were similar between treatment groups at baseline. History of ophthalmic conditions reported in more than two subjects included blepharitis (seven [4.7\%]), corneal scar (four [2.7\%]), corneal abrasion (three [2.0\%]), dry eye (three $[2.0 \%]$ ), and pinguecula (three [2.0\%]).

\section{Efficacy evaluation}

\section{Primary efficacy variable}

In the PP population, mean (SD) OSDI scores were 3.9 (4.6) in the CMC-HA group and 4.1 (5.0) in the CMC group at baseline. OSDI scores increased post-LASIK surgery, peaking at day 10 , then steadily decreased at subsequent follow-up visits (Figure 1). At day 90, mean (SD) OSDI scores were 7.0 (8.5) in the CMC-HA group and 6.6 (7.1) in the CMC group. At baseline and day 90, mean OSDI scores were within the normal range (0-12) for both treatment groups. At day 90 , the difference in OSDI scores was 0.4 (95\% CI, -2.4, 3.2; $P=0.775)$; the upper limit of the $95 \%$ CI was below the prespecified clinical margin of 4.7 units, demonstrating that CMC-HA provided equivalent relief of symptoms and was statistically noninferior to $\mathrm{CMC}$.

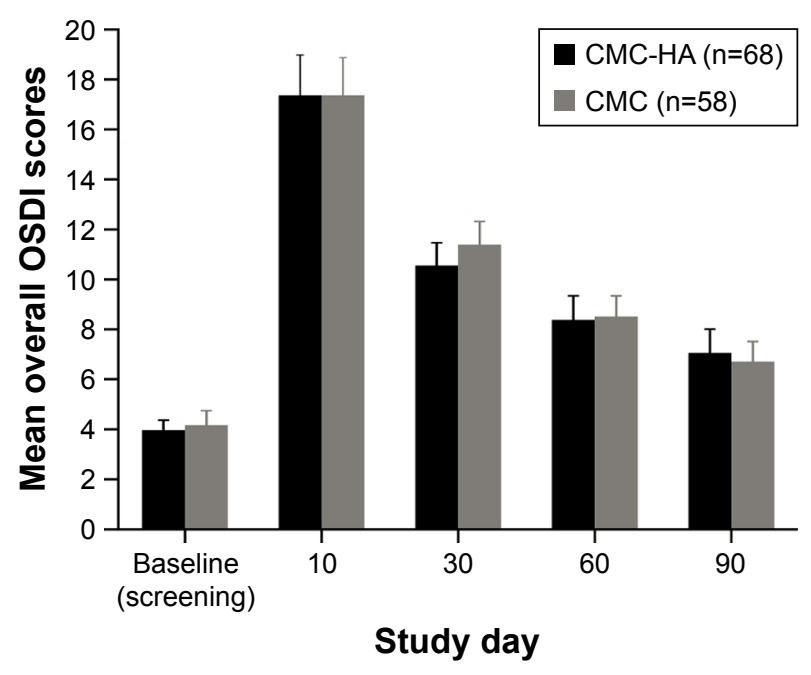

Figure I Mean overall Ocular Surface Disease Index ${ }^{\odot}$ (OSDI) scores at study visits. Note: Error bars indicate standard error of the mean (per-protocol population). Abbreviations: CMC, carboxymethylcellulose 0.5\%; CMC-HA, carboxymethylcellulose $0.5 \%$, hyaluronic acid $0.1 \%$.
There were no significant differences in the mean (SD) change from baseline in OSDI score at day 90 between the treatment groups (3.1 [9.1] for CMC-HA and 2.5 [8.1] for $\mathrm{CMC}$ ), and no between-group differences in other analyses of OSDI scores.

\section{Results of preoperative refraction subgroups}

Manifest refraction spherical equivalent was similar at baseline between the two treatment groups ( -3.72 [range, -7.88 to 3.00] CMC-HA; -3.79 [range, -8.00 to 4.75 ] CMC). Of all enrolled subjects, at baseline, 119 were stratified as standard myopes, 23 as moderate myopes, and six as hyperopes. Similar to the overall population, subgroup analyses based on baseline refractive strata demonstrated no significant differences in OSDI scores between CMC-HA and CMC treatment groups. Within the CMC group, hyperopes $(n=3)$ had significantly greater changes from baseline in OSDI scores at days 60 and 90 than standard myopes (n=59; $P<0.001$ and $P=0.025$, respectively) and moderate myopes $(\mathrm{n}=11$; $P=0.013$ and $P=0.032$, respectively), but this effect was not observed in the CMC-HA group (Table 3).

\section{Secondary efficacy variables}

Mean (SD) UDVA on day 2 post-LASIK surgery was 51.1 (10.0) letters for the CMC-HA group and 53.1 (9.5) letters for the CMC group (PP population). Following day 2, visual acuity increased at all follow-up visits after LASIK in both treatment groups $(P \leq 0.047)$, with higher mean improvements from day 2 in the CMC-HA group, and a statistically significant difference was observed between groups at day 30 $(P=0.013)$ (Figure 2). At day 90, the mean (SD) change from day 2 in visual acuity was 5.8 (5.2) letters in the CMC-HA group and 4.7 (6.0) letters in the CMC group $(P=0.285)$.

In both treatment groups, corneal fluorescein staining increased (worsened) after LASIK from a mean (SD) score of 0.9 (1.3) for the CMC-HA group and 1.2 (1.3) for the CMC group at baseline and peaked at day 10 , before progressively decreasing (improving) up to day 90 (Figure 3A). Schirmer's scores generally increased in both CMC-HA and CMC groups, but there were no significant differences compared with baseline at day 90 (Figure 3B). Mean (SD) TBUT was higher in the CMC-HA group compared with the CMC group at baseline (11.9 [11.7] vs 9.3 [5.1] seconds; $P=0.084$ ) and at each follow-up study visit; no significant differences were observed at any follow-up visit up to day 90 compared with baseline in either treatment group (Figure 3C).

Patient surveys revealed that burning/stinging, grittiness/ foreign body sensation, dryness, difficult/uncomfortable vision, and overall ocular pain/discomfort scores worsened 
Table 3 OSDI scores at baseline (screening visit) and follow-up visits based on preoperative refractive error stratification (ITT population)

\begin{tabular}{|c|c|c|c|c|c|c|}
\hline \multirow{2}{*}{$\begin{array}{l}\text { Treatment/ } \\
\text { study visit }\end{array}$} & \multicolumn{3}{|c|}{ OSDI by refractive strata, mean (SD) } & \multicolumn{3}{|c|}{ Difference between strata $(95 \% \mathrm{Cl})$} \\
\hline & $\begin{array}{l}\text { Standard } \\
\text { myope }\end{array}$ & $\begin{array}{l}\text { Moderate } \\
\text { myope }\end{array}$ & Hyperope & $\begin{array}{l}\text { Standard myope } \\
\text { vs hyperope }\end{array}$ & $\begin{array}{l}\text { Moderate myope } \\
\text { vs hyperope }\end{array}$ & $\begin{array}{l}\text { Standard myope } \\
\text { vs moderate myope }\end{array}$ \\
\hline CMC-HA & $n=60$ & $n=12$ & $\mathrm{n}=3$ & & & \\
\hline Baseline & $3.7(4.7)$ & $5.7(5.3)$ & $5.6(5.2)$ & $-1.9(-5.8,1.9)$ & $0.1(-4.1,4.3)$ & $-2.0(-4.6,0.6)$ \\
\hline Day 10 & $12.6(14.3)$ & $8.2(10.7)$ & $12.2(17.4)$ & $0.4(-10.4,11.1)$ & $-4.1(-15.8,7.7)$ & $4.4(-2.8,11.7)$ \\
\hline Day 30 & $6.4(9.9)$ & $5.6(7.5)$ & $6.2(7.2)$ & $0.2(-7.0,7.4)$ & $-0.6(-8.5,7.2)$ & $0.8(-4.0,5.7)$ \\
\hline Day 60 & $4.2(9.3)$ & $3.6(8.1)$ & $2.8(2.4)$ & $1.4(-5.4,8.2)$ & $0.8(-6.7,8.2)$ & $0.6(-4.0,5.2)$ \\
\hline Day 90 & $2.7(9.1)$ & $4.5(9.5)$ & $3.2(3.2)$ & $-0.5(-7.5,6.5)$ & I.3 $(-6.3,9.0)$ & $-1.8(-6.5,2.9)$ \\
\hline CMC & $n=59$ & $\mathrm{n}=\mathrm{II}$ & $\mathrm{n}=3$ & & & \\
\hline Baseline & $3.9(4.8)$ & $4.1(5.3)$ & $5.6(9.6)$ & $-1.6(-5.8,2.6)$ & $-1.5(-6.1,3.2)$ & $-0.2(-3.1,2.8)$ \\
\hline Day 10 & $12.0(12.9)$ & $17.9(12.8)$ & I8.3 (23.8) & $-6.3(-17.2,4.6)$ & $-0.4(-12.5,11.7)$ & $-5.9(-13.5,1.7)$ \\
\hline Day 30 & $6.9(8.2)$ & $7.1(9.8)$ & $14.6(20.9)$ & $-7.7(-15.5,0.2)$ & $-7.4(-16.1,1.2)$ & $-0.2(-5.7,5.2)$ \\
\hline Day 60 & $3.5(6.9)$ & $5.6(7.5)$ & $14.6(16.6)$ & $-I I . I(-17.4,-4.8)^{*}$ & $-9.0(-16.0,-2.0)^{*}$ & $-2.1(-6.6,2.3)$ \\
\hline Day 90 & $3.1(8.0)$ & $2.6(7.1)$ & II.I (I8.2) & $-8.1(-15.1,-1.1)^{*}$ & $-8.5(-16.2,-0.8)^{*}$ & $0.5(-4.4,5.3)$ \\
\hline
\end{tabular}

Note: $* P<0.05$ for the difference between strata by one-way ANOVA model with fixed effect of strata and using the weighted least square method.

Abbreviations: CMC, carboxymethylcellulose 0.5\%; CMC-HA, carboxymethylcellulose $0.5 \%$, hyaluronic acid $0.1 \%$; ITT, intent-to-treat; OSDI, Ocular Surface Disease Index ${ }^{\odot}$

from baseline, peaking at day 2 following LASIK in both treatment groups. Ocular symptom scores gradually improved at follow-up visits in both CMC-HA and CMC groups with no significant differences observed from baseline at day 90, except for dryness in both treatment groups (Table 4). Assessment of the short- and long-term acceptability of study eye drops showed no differences between

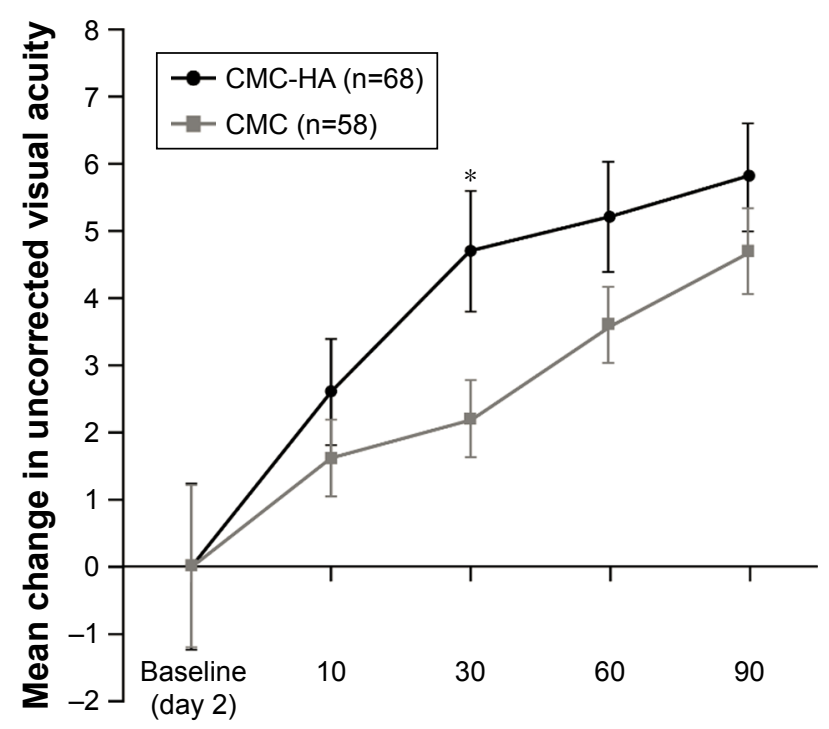

\section{Study day}

Figure 2 Change in mean uncorrected visual acuity in the worse eye post-LASIK surgery.

Notes: Error bars indicate standard error of the mean (per-protocol population). $* P=0.013$ for between group difference in the change from day 2 in total number of letters read correctly (ANOVA model with fixed effects of treatment and the stratification factor using the type III sum of squares).

Abbreviations: CMC, carboxymethylcellulose 0.5\%; CMC-HA, carboxymethylcellulose $0.5 \%$, hyaluronic acid $0.1 \%$; LASIK, laser-assisted in situ keratomileusis.
CMC-HA and $\mathrm{CMC}$ in the average response to each of the six items assessed $(P>0.188)$.

The use of study eye drops declined over time in both treatment groups. At day 10 the mean (SD) number of times the study product was used per day over the previous week was 8.4 (2.8) in the CMC-HA group and 9.0 (3.3) in the CMC group, and at day 90 product usage decreased to 3.6 (2.4) and 3.9 (2.3) times per day, respectively. Patientreported drop use was consistent with dosage assignment by the investigator, which shifted to lower levels of dosing later after LASIK surgery.

\section{Safety evaluation}

Significantly fewer subjects in the CMC-HA group (16 [21.3\%]) compared with the CMC group (27 [37.0\%]) reported experiencing AEs of any causality $(P=0.036)$. In addition, fewer subjects reported ocular AEs in the CMC-HA group (six [8.0\%]) than in the CMC group (12 [16.4\%]); the most common ocular AEs were blepharitis reported in seven subjects (one [1.3\%] with CMC-HA, six [8.2\%] with $\mathrm{CMC}$ ) and punctate keratitis reported in six subjects (three [4.0\%] with CMC-HA, three [4.1\%] with $\mathrm{CMC}$ ). The incidence of treatment-related AEs was low in both groups (one [1.3\%] dysgeusia with $\mathrm{CMC}-\mathrm{HA}$, one [1.4\%] blepharitis with $\mathrm{CMC}$ ), and no subjects discontinued the study because of AEs. Clinically significant (more than one severity grade increase [worsening] from baseline) biomicroscopy findings were equally reported in the CMC-HA (34 [45.3\%]) and CMC (38 [52.1\%]) groups; such findings are typical in post-LASIK patients. 


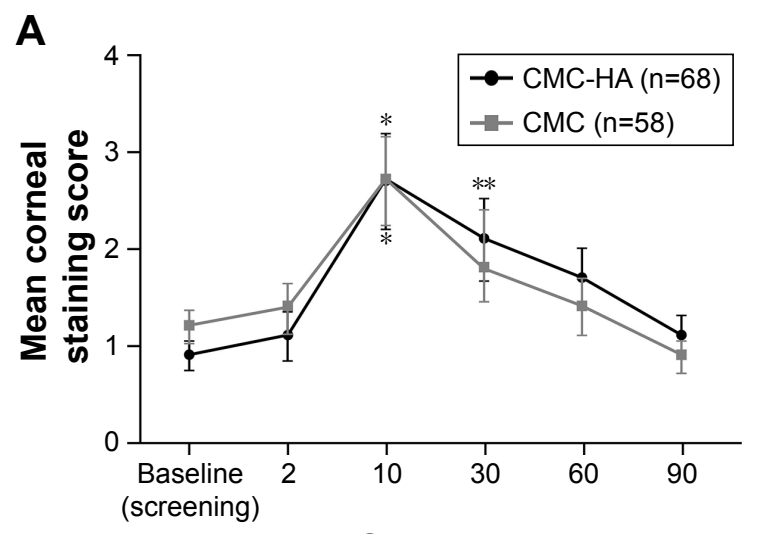

Study day

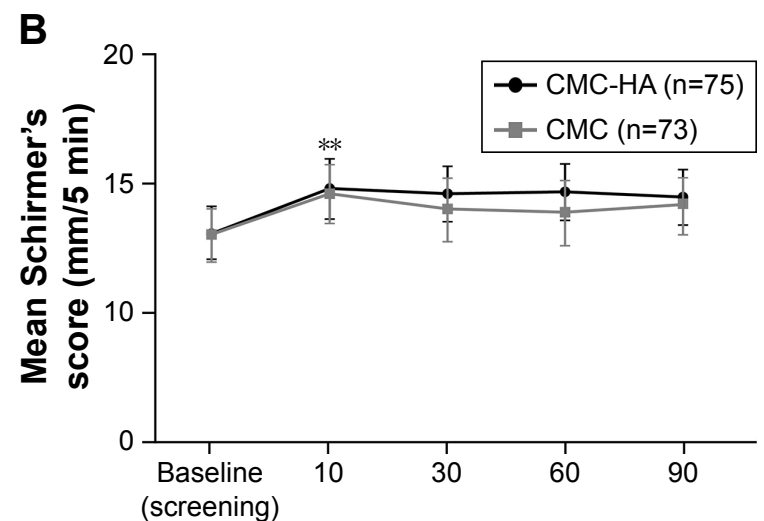

Study day

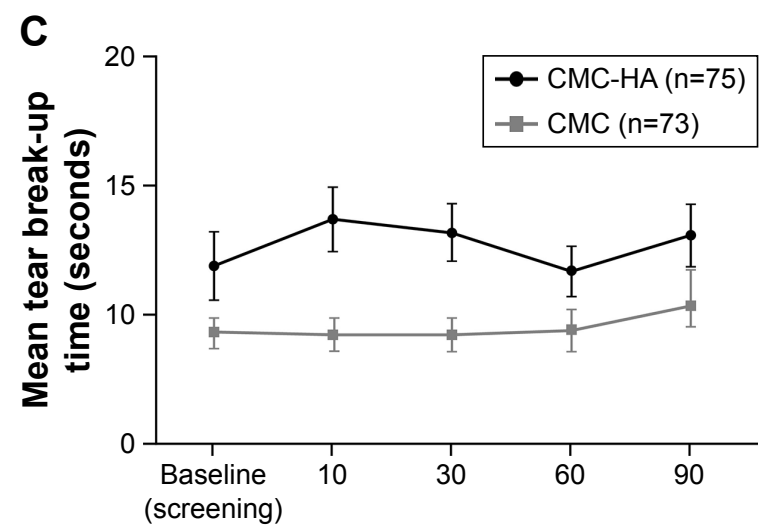

Study day

Figure 3 Mean (A) corneal staining, (B) Schirmer's test score, and (C) tear break-up time at study visits.

Notes: Error bars indicate standard error of the mean $(\mathbf{A})$, per-protocol population; (B and $\mathbf{C})$, intent-to-treat population. $* P<0.01$; $* * P<0.05$ for within-group comparison with baseline (paired $t$-test).

Abbreviations: CMC, carboxymethylcellulose $0.5 \%$; CMC-HA, carboxymethylcellulose $0.5 \%$, hyaluronic acid $0.1 \%$.

Baseline IOP was similar between groups: mean (SD) 15.4 (2.5) $\mathrm{mmHg}$ for the CMC-HA group and 15.2 (2.8) $\mathrm{mmHg}$ for the CMC group. Both treatment groups had significant decreases in measured IOP by day 90 (mean change from baseline, $-2.6 \mathrm{mmHg}$ for both treatment groups; $P<0.001$ for within-group differences). This result was expected because of corneal thinning from the LASIK procedure.

At baseline, CDVA was similar between treatment groups, and no differences were observed in the change from baseline in the total number of letters read at all follow-up

Table 4 Severity of ocular symptoms at baseline (screening visit) and follow-up study visits after LASIK (ITT population)

\begin{tabular}{|c|c|c|c|c|c|c|}
\hline \multirow[t]{4}{*}{ Ocular symptom } & \multirow{3}{*}{\multicolumn{3}{|c|}{$\begin{array}{l}\text { CMC-HA (n=75) } \\
\text { Mean (SD) score } \\
P \text {-value* }\end{array}$}} & \multirow{3}{*}{\multicolumn{3}{|c|}{$\begin{array}{l}\text { CMC }(n=73) \\
\text { Mean (SD) score } \\
\text { P-value* }\end{array}$}} \\
\hline & & & & & & \\
\hline & & & & & & \\
\hline & Baseline & Day 2 & Day 90 & Baseline & Day 2 & Day 90 \\
\hline \multirow{2}{*}{ Burning/stinging } & $2.4(3.8)$ & $29.6(28.6)$ & $2.7(6.5)$ & $3.1(10.9)$ & $31.5(29.2)$ & $2.3(10.1)$ \\
\hline & - & $<0.001$ & 0.692 & - & $<0.001$ & 0.647 \\
\hline Grittiness/foreign & $2.7(5.2)$ & $30.3(28.0)$ & $4.5(8.1)$ & $2.2(10.3)$ & $29.6(26.7)$ & $2.5(4.9)$ \\
\hline body sensation & - & $<0.001$ & 0.110 & - & $<0.001$ & 0.811 \\
\hline \multirow[t]{2}{*}{ Dryness } & $4.9(7.4)$ & $19.7(22.1)$ & $8.4(11.9)$ & $7.1(14.0)$ & $22.3(24.4)$ & II.3 (15.3) \\
\hline & - & $<0.001$ & 0.023 & - & $<0.001$ & 0.047 \\
\hline Difficult/ & $2.3(8.8)$ & $24.8(23.3)$ & $5.2(13.2)$ & $3.3(10.9)$ & $33.2(27.2)$ & $2.2(5.0)$ \\
\hline uncomfortable vision & - & $<0.001$ & 0.124 & - & $<0.001$ & 0.384 \\
\hline Overall ocular pain/ & $2.1(6.1)$ & $26.3(25.8)$ & $1.9(4.3)$ & $2.3(11.4)$ & $27.4(27.3)$ & $1.9(5.6)$ \\
\hline discomfort & - & $<0.001$ & 0.816 & - & $<0.001$ & 0.791 \\
\hline
\end{tabular}

Note: $* P$-value for within-group comparison to baseline (paired $t$-test).

Abbreviations: LASIK, laser-assisted in situ keratomileusis; CMC, carboxymethylcellulose $0.5 \%$; CMC-HA, carboxymethylcellulose $0.5 \%$, hyaluronic acid $0.1 \%$; ITT, intentto-treat. 
visits ( $P \geq 0.139$ for between-group comparisons). Significant within-group improvements in CDVA from baseline were recorded in both CMC-HA (1.8 [3.2] letters; $P<0.001)$ and CMC (1.2 [4.0] letters; $P=0.013)$ groups by day 90 .

\section{Discussion}

LASIK is considered to disrupt the lacrimal functional unit that maintains normal tear production and lubrication, through severing of corneal nerves and direct ocular surface effects during the procedure. ${ }^{17}$ Approximately 50\% of subjects have dry eye signs and symptoms as early as 1 week after LASIK. ${ }^{18}$ Albietz et al $^{19}$ reported diminished myopic outcomes in chronic dry eye patients more frequently than in normal patients. Moreover, visual regression after LASIK was related to chronic dry eye, highlighting the importance of adequate postoperative dry eye management. ${ }^{19}$ Post-LASIK dry eye symptoms are typically managed with artificial tears. Punctal plug occlusion, topical cyclosporine A, topical steroids, autologous serum tears, and scleral lenses may be used to control more severe dry eye following LASIK. ${ }^{1}$ This study looked at the efficacy and safety of a preservative-free, multi-ingredient CMC-HA formulation. The CMC-only formula was selected as the comparator since it is considered a standard lubricating eye drop post-LASIK.

OSDI scores increased following LASIK surgery in both CMC-HA and CMC treatment groups, peaking at day 10 , then progressively improving to normal levels (overall score <13). ${ }^{14}$ Other studies have reported similar significant increases in OSDI scores after femtosecond laserassisted LASIK surgery, ${ }^{20,21}$ which can remain elevated up to 6 months. ${ }^{20}$ In this study, the new eye drop formulation containing $\mathrm{CMC}$ and $\mathrm{HA}$ met the primary efficacy endpoint and was noninferior to a formulation of CMC alone for change in OSDI score from baseline at day 90.

Among the refractive status groups (standard myope, moderate myope, hyperope), post hoc analyses revealed larger increases in OSDI scores from baseline to days 60 and 90 among the hyperopic eyes compared with standard and moderate myopic eyes in the $\mathrm{CMC}$ group, but no difference in the CMC-HA group. Although this finding must be interpreted with caution because of the small number of subjects in the hyperope subgroup, it is consistent with the greater degree of peripheral ablation for hyperopic treatment that is linked to post-LASIK dry eye. ${ }^{3,18}$ The cornea is steepened during hyperopic treatment with more tear instability resulting over the central cornea. ${ }^{22,23}$ The HA polymer and other ingredients in the CMC-HA formulation may provide improved benefit to the post-operative corneal surface than the CMC-only formula. Additional studies of hyperopic LASIK patients and those at higher risk of dry eye are warranted to further delineate the beneficial role of CMC-HA eye drops.

Corneal staining also worsened after LASIK and was followed by improvements over time, consistent with overall recovery of the corneal surface. Although there was a marginally higher mean TBUT in the CMC-HA group compared to the CMC group at baseline, this difference was not statistically significant. Schirmer's scores and TBUT generally increased following surgery, and were not significantly different from baseline or between groups by day 90 . Clinical signs of dry eye have been reported as early as 1 week after LASIK surgery, and compromised tear function can persist for a month; signs can remain for 6 months to 1 year. . $^{2,3,5,24}$ There were no significant differences between the CMC-HA and $\mathrm{CMC}$ treatment groups in any of these measures.

Importantly, in the context of post-LASIK care, UDVA improved more rapidly following surgery in the CMC-HA group compared with $\mathrm{CMC}$, with higher mean improvements observed in the CMC-HA group at all study visits, reaching statistical significance at day $30(P=0.013)$. This observation may reflect a greater rate of corneal surface epithelial healing combined with synergistic effects of CMC and HA such as increased drop viscosity, better ocular retention, tear film stabilization, and activation of the CD-44 receptor by $\mathrm{HA}^{25-28}$ leading to improved surface optics. Combination CMC and HA has been shown to reduce goblet cell loss in a mouse model of dry eye, ${ }^{10}$ a mechanism that may contribute to the positive outcomes observed in this study, as goblet cell loss is associated with dryness post-LASIK. ${ }^{23,29-31}$ The safety profile of CMC-HA was also incrementally improved compared with CMC, with fewer total AEs of any causality, ocular AEs, and biomicroscopy findings.

With a greater understanding of the roles of tears, tear film osmolarity, and ocular surface inflammation in dry eye disease, ${ }^{32-34}$ new artificial tear formulations have enhanced interactions with ocular surface cells by preventing loss of cell volume, cellular stress and inflammation, and by eliminating damaging preservatives. Artificial tear formulations consisting of $\mathrm{CMC}$ or $\mathrm{HA}$ alone have been shown to be effective in reducing signs and symptoms of post-LASIK dry eye.$^{6-8}$ A combination of diquafosol tetrasodium and HA has also been reported to potentially benefit vision and improve dry eye symptoms after LASIK. ${ }^{35}$ The benefit of osmoprotectants in lubricant drops used to treat dry eye post-LASIK has also been demonstrated, with a significant improvement in symptoms reported following treatment with HA and adjuvant trehalose compared with HA alone. ${ }^{36}$

The current study is the only one to our knowledge, that looks at the combination of CMC and HA in post-LASIK 
dry eye. The novel artificial tear containing CMC and HA, as well as glycerin, L-carnitine, and erythritol as organic osmolytes, was well tolerated by subjects post-LASIK surgery, and its overall performance suggests that the presence of HA may enhance recovery of the ocular surface epithelium, improve surface optics, and further promote visual recovery in comparison with the standard CMC eye drop. This formulation should be considered a suitable treatment option for management of post-LASIK dry eye.

\section{Acknowledgments}

This study was sponsored by Allergan plc, Dublin, Ireland. Writing and editorial assistance was provided to the authors by Kakuri M Omari, PhD, of Evidence Scientific Solutions, Philadelphia, PA, USA, and was funded by Allergan plc. Neither honoraria nor payments were made for authorship. The authors would like to thank the patients who participated in this study and acknowledge the investigators who contributed to the study conduct. The investigators included: Canada: Eser Adiguzel, Montreal, QC; Michael Bense, St John's, NL; W Bruce Jackson, Ottawa, ON; Jeffrey Chambers, Kelowna, BC; Clara Chan, Toronto, ON; Sameh Fanous, Saint-Laurent, QC; Sheldon Herzig, Toronto, ON; Chris Jackman, St John's, NL; Hugh Jellie, Waterloo, ON; Joseph King, Edmonton, AB; Christoph Kranemann, Toronto, ON; Andrew Taylor, Niagara Falls, ON; Avi Wallerstein, Montreal, QC; James Wiens, Winnipeg, MB. Australia: Patrick Versace, Bondi Junction, NSW.

\section{Disclosure}

Avi Wallerstein received research funding for the conduct of the study. W Bruce Jackson received research funding for the conduct of the study and has served as a consultant to Allergan plc. Amir Moezzi received research funding from Allergan plc for the conduct of the study. Peter A Simmons was an employee of Allergan plc, Irvine, CA, USA at the time the study was conducted and has patents licensed to Allergan plc relevant to the reported study. Hugh Lin was an employee of Allergan plc, Irvine, CA, USA at the time the study was conducted and is currently a medical director at Genentech, a company that does operate in the ophthalmology space. Jeffrey Chambers reports no conflicts of interest in this work.

\section{References}

1. Raoof D, Pineda R. Dry eye after laser in-situ keratomileusis. Semin Ophthalmol. 2014;29(5-6):358-362.

2. Solomon KD, Holzer MP, Sandoval HP, et al. Refractive surgery survey 2001. J Cataract Refract Surg. 2002;28(2):346-355.

3. Shoja MR, Besharati MR. Dry eye after LASIK for myopia: incidence and risk factors. Eur J Ophthalmol. 2007;17(1):1-6.
4. Chao C, Golebiowski B, Stapleton F. The role of corneal innervation in LASIK-induced neuropathic dry eye. Ocul Surf. 2014;12(1):32-45.

5. Bower KS, Sia RK, Ryan DS, Mines MJ, Dartt DA. Chronic dry eye in photorefractive keratectomy and laser in situ keratomileusis: manifestations, incidence, and predictive factors. J Cataract Refract Surg. 2015;41(12):2624-2634.

6. Lenton LM, Albietz JM. Effect of carmellose-based artificial tears on the ocular surface in eyes after laser in situ keratomileusis. $J$ Refract Surg. 1999;15(2 Suppl):S227-S231.

7. Albietz JM, Lenton LM, McLennan SG, Earl ML. A comparison of the effect of refresh plus and bion tears on dry eye symptoms and ocular surface health in myopic LASIK patients. CLAO J. 2002;28(2):96-100.

8. Astakhov YS, Astakhov SY, Lisochkina AB. Assessment of dry eye signs and symptoms and ocular tolerance of a preservative-free lacrimal substitute $\left(\right.$ Hylabak $^{\circledR}$ ) versus a preserved lacrimal substitute $\left(\right.$ Systane $\left.^{\circledR}\right)$ used for 3 months in patients after LASIK. Clin Ophthalmol. 2013;7:2289-2297.

9. Gomes JA, Amankwah R, Powell-Richards A, Dua HS. Sodium hyaluronate (hyaluronic acid) promotes migration of human corneal epithelial cells in vitro. Br J Ophthalmol. 2004;88(6):821-825.

10. She Y, Li J, Xiao B, et al. Evaluation of a novel artificial tear in the prevention and treatment of dry eye in an animal model. JOcul Pharmacol Ther. 2015;31(9):525-530.

11. Simmons PA, Vehige JG. Investigating the potential benefits of a new artificial tear formulation combining two polymers. Clin Ophthalmol. 2017;11:1637-1642.

12. Corrales RM, Luo LH, Chang EY, Pflugfelder SC. Effects of osmoprotectants on hyperosmolar stress in cultured human corneal epithelial cells. Cornea. 2008;27(5):574-579.

13. Simmons PA, Liu H, Carlisle-Wilcox C, Vehige JG. Efficacy and safety of two new formulations of artificial tears in subjects with dry eye disease: a 3-month, multicenter, active-controlled, randomized trial. Clin Ophthalmol. 2015;9:665-675.

14. Schiffman RM, Christianson MD, Jacobsen G, Hirsch JD, Reis BL. Reliability and validity of the Ocular Surface Disease Index. Arch Ophthalmol. 2000;118(5):615-621.

15. Chen JJ, Rao K, Pflugfelder SC. Corneal epithelial opacity in dysfunctional tear syndrome. Am J Ophthalmol. 2009;148(3):376-382.

16. Miller KL, Walt JG, Mink DR, et al. Minimal clinically important difference for the Ocular Surface Disease Index. Arch Ophthalmol. 2010; 128(1):94-101.

17. Nettune GR, Pflugfelder SC. Post-LASIK tear dysfunction and dysesthesia. Ocul Surf. 2010;8(3):135-145.

18. De Paiva CS, Chen Z, Koch DD, et al. The incidence and risk factors for developing dry eye after myopic LASIK. Am J Ophthalmol. 2006; 141(3):438-445.

19. Albietz JM, Lenton LM, McLennan SG. Chronic dry eye and regression after laser in situ keratomileusis for myopia. J Cataract Refract Surg. 2004;30(3):675-684.

20. Huang JC, Sun CC, Chang CK, Ma DH, Lin YF. Effect of hinge position on corneal sensation and dry eye parameters after femtosecond laser-assisted LASIK. J Refract Surg. 2012;28(9):625-631.

21. Li M, Zhao J, Shen Y, et al. Comparison of dry eye and corneal sensitivity between small incision lenticule extraction and femtosecond LASIK for myopia. PLoS One. 2013;8(10):e77797.

22. Lindstrom RL, Hardten DR, Houtman DM, et al. Six-month results of hyperopic and astigmatic LASIK in eyes with primary and secondary hyperopia. Trans Am Ophthalmol Soc. 1999;97:241-260.

23. Albietz JM, Lenton LM, McLennan SG. Effect of laser in situ keratomileusis for hyperopia on tear film and ocular surface. J Refract Surg. 2002;18(2):113-123.

24. Battat L, Macri A, Dursun D, Pflugfelder SC. Effects of laser in situ keratomileusis on tear production, clearance, and the ocular surface. Ophthalmology. 2001;108(7):1230-1235.

25. Peach RJ, Hollenbaugh D, Stamenkovic I, Aruffo A. Identification of hyaluronic acid binding sites in the extracellular domain of CD44. J Cell Biol. 1993;122(1):257-264. 
26. Mackay CR, Terpe HJ, Stauder R, Marston WL, Stark H, Günthert U. Expression and modulation of CD44 variant isoforms in humans. J Cell Biol. 1994;124(1-2):71-82.

27. Brignole F, Pisella PJ, Dupas B, Baeyens V, Baudouin C. Efficacy and safety of $0.18 \%$ sodium hyaluronate in patients with moderate dry eye syndrome and superficial keratitis. Graefes Arch Clin Exp Ophthalmol. 2005;243(6):531-538.

28. Lerner LE, Schwartz DM, Hwang DG, Howes EL, Stern R. Hyaluronan and CD44 in the human cornea and limbal conjunctiva. Exp Eye Res. 1998;67(4):481-484.

29. Albietz JM, McLennan SG, Lenton LM. Ocular surface management of photorefractive keratectomy and laser in situ keratomileusis. J Refract Surg. 2003;19(6):636-644.

30. Rodriguez AE, Rodriguez-Prats JL, Hamdi IM, Galal A, Awadalla M, Alio JL. Comparison of goblet cell density after femtosecond laser and mechanical microkeratome in LASIK. Invest Ophthalmol Vis Sci. 2007;48(6):2570-2575.
31. Ryan DS, Bower KS, Sia RK, et al. Goblet cell response after photorefractive keratectomy and laser in situ keratomileusis. J Cataract Refract Surg. 2016;42(8):1181-1189.

32. Baudouin C, Aragona P, Messmer EM, et al. Role of hyperosmolarity in the pathogenesis and management of dry eye disease: proceedings of the OCEAN group meeting. Ocul Surf. 2013;11(4):246-258.

33. Pflugfelder SC, Corrales RM, de Paiva CS. T helper cytokines in dry eye disease. Exp Eye Res. 2013;117:118-125.

34. Stevenson W, Chauhan SK, Dana R. Dry eye disease: an immune-mediated ocular surface disorder. Arch Ophthalmol. 2012;130(1):90-100.

35. Toda I, Ide T, Fukumoto T, Ichihashi Y, Tsubota K. Combination therapy with diquafosol tetrasodium and sodium hyaluronate in patients with dry eye after laser in situ keratomileusis. Am J Ophthalmol. 2014; 157(3):616.e1-622.e1

36. Mateo Orobia AJ, Casas Pascual P, Cristobal Bescos JA, et al. Effects of $3 \%$ trehalose as an adjuvant treatment after LASIK. Clin Ophthalmol. 2017; 11:347-353 


\section{Supplementary material}

Table SI Ethics committees providing study protocol approval

\begin{tabular}{|c|c|}
\hline Australian study site & Investigator/site \\
\hline Bellberry Human Research Ethics Committee & Patrick Versace, Bondi Junction, NSW \\
\hline \multicolumn{2}{|l|}{229 Greenhill Road } \\
\hline \multicolumn{2}{|l|}{ Dulwich SA 5065, Australia } \\
\hline Canadian study sites & Investigator/site \\
\hline Clinical Research Ethics Committee & Hugh Jellie, Waterloo, ON \\
\hline \multicolumn{2}{|l|}{ University of Waterloo } \\
\hline \multicolumn{2}{|l|}{200 University Avenue West } \\
\hline \multicolumn{2}{|l|}{ Waterloo, ON N2L 3GI, Canada } \\
\hline Health Research Ethics Authority & Michael Bense, St John's, NL \\
\hline 95 Bonaventure Avenue, Suite 200, 2nd Floor & Chris Jackman, St John's, NL \\
\hline \multicolumn{2}{|l|}{ St John's, Newfoundland and Labrador AIB 2X5, Canada } \\
\hline Health Research Ethics Board of Alberta - Clinical Trials and Research Ethics Review Committees & Joseph King, Edmonton, AB \\
\hline \multicolumn{2}{|l|}{ 1500, $10104-103$ Avenue NW } \\
\hline \multicolumn{2}{|l|}{ Edmonton, AB T5J 4A7, Canada } \\
\hline Ottawa Health Science Network-Research Ethics Board & W Bruce Jackson, Ottawa, ON \\
\hline \multicolumn{2}{|l|}{725 Parkdale Avenue, Suite 4II } \\
\hline \multicolumn{2}{|l|}{ Ottawa, ON KIY 4E9, Canada } \\
\hline Schulman Associates Institutional Review Board, Inc & Jeffrey Chambers, Kelowna, BC \\
\hline 4445 Lake Forest Drive, Suite 300 & Clara Chan, Toronto, ON \\
\hline \multirow[t]{6}{*}{ Cincinnati, OH 45242, USA } & Sameh Fanous, Saint-Laurent, QC \\
\hline & Sheldon Herzig, Toronto, ON \\
\hline & Christoph Kranemann, Toronto, ON \\
\hline & Andrew Taylor, Niagara Falls, ON \\
\hline & Avi Wallerstein, Montreal, QC \\
\hline & James Wiens, Winnipeg, MB \\
\hline
\end{tabular}

Clinical Ophthalmology

\section{Publish your work in this journal}

Clinical Ophthalmology is an international, peer-reviewed journal covering all subspecialties within ophthalmology. Key topics include: Optometry; Visual science; Pharmacology and drug therapy in eye diseases; Basic Sciences; Primary and Secondary eye care; Patient Safety and Quality of Care Improvements. This journal is indexed on

Submit your manuscript here: http://www.dovepress.com/clinical-ophthalmology-journal
Dovepress

PubMed Central and CAS, and is the official journal of The Society of Clinical Ophthalmology (SCO). The manuscript management system is completely online and includes a very quick and fair peer-review system, which is all easy to use. Visit http://www.dovepress.com/ testimonials.php to read real quotes from published authors. 